\title{
Genetic Analysis of the Roles of Hh, FGF8, and Nodal Signaling during Catecholaminergic System Development in the Zebrafish Brain
}

\author{
Jochen Holzschuh, Giselbert Hauptmann, and Wolfgang Driever \\ Developmental Biology, Institute Biology 1, University of Freiburg, D-79104 Freiburg, Germany
}

\begin{abstract}
CNS catecholaminergic neurons can be distinguished by their neurotransmitters as dopaminergic or noradrenergic and form in distinct regions at characteristic embryonic stages. This raises the question of whether all catecholaminergic neurons of one transmitter type are specified by the same set of factors. Therefore, we performed genetic analyses to define signaling requirements for the specification of distinct clusters of catecholaminergic neurons in zebrafish. In mutants affecting midbrain-hindbrain boundary (MHB) organizer formation, the earliest ventral diencephalic dopaminergic neurons appear normal. However, after $2 \mathrm{~d}$ of development, we observed fewer cells than in wild types, which suggests that the MHB provides proliferation or survival factors rather than specifying ventral diencephalic dopaminergic clusters. In hedgehog $(\mathrm{Hh})$ pathway mutants, the formation of catecholaminergic neurons is affected only in the pretectal cluster. Surprisingly, neither fibroblast growth factor 8 (FGF8) alone nor in combination with Hh signaling is required for specification of early developing dopaminergic neurons. We analyzed the formation of prosomeric territories in the forebrain of Hh and Nodal pathway mutants to determine whether the absence of specific dopaminergic clusters may be caused by early patterning defects ablating corresponding parts of the CNS. In Nodal pathway mutants, ventral diencephalic and pretectal catecholaminergic neurons fail to develop, whereas both anatomical structures form at least in part. This suggests that Nodal signaling is required for catecholaminergic neuron specification. In summary, our results do not support the previously suggested dominant roles for sonic hedgehog and Fgf8 in specification of the first catecholaminergic neurons, but instead indicate a novel role for Nodal signaling in this process.
\end{abstract}

Key words: catecholaminergic system; dopaminergic neurons; Danio rerio; sonic hedgehog; nodal; fibroblast growth factor 8; forebrain; pretectum; hypothalamus; locus coeruleus; medulla oblongata

\section{Introduction}

The vertebrate CNS catecholaminergic (CA) system participates in a variety of tasks including motor coordination, mood regulation, and cognitive function. Reflecting the complexity of the CA system, distinct groups of CA neurons form at various developmental stages (for review, see Smeets and Reiner, 1994). Several transcription factors have been shown to contribute to their specification, including Ptx3 (Smidt et al., 1997), Nurr1 (Zetterstrom et al., 1997), Lmx1b (Smidt et al., 2000), and Phox2b (for review, see Hynes and Rosenthal, 2000; Lee et al., 2000; Pattyn et al., 2000). Experimental embryology studies indicate that mesencephalic dopaminergic (DA) neurons depend on signals from the midbrain-hindbrain boundary (MHB) and floor plate. In rat explant cultures, a floor plate transplant can induce DA neuron

\footnotetext{
Received Nov. 7, 2002; revised April 10, 2003; accepted April 14, 2003.

This work was supported by Deutsche Forschungsgemeinschaft Grants SFB 505 TP B7 and SFB 592 TP A3 (W.D.). We thank Dr. Z. Varga for complementation with $5 m u^{6641}$, Dr. D. Meyer for MZsur fish, and A. Fiebig for help during the initial phase of the project. We thank Dr. S. Ryu, Dr. Z. Varga, Dr. K. Lunde, Dr. D. Meyer, and K. Dürr for helpful critique of this manuscript and discussion. S. Götter and R. Schlenvogt provided expert care of the fish.

Correspondence should be addressed to Dr. W. Driever, Developmental Biology, Institute Biology 1, University of Freiburg, Hauptstrasse 1, D-79104 Freiburg, Germany. E-mail: driever@biologie.uni-freiburg.de.

J. Holzschuh's present address: Department of Developmental and Cell Biology, University of California, Irvine, CA 92697.

Copyright $\odot 2003$ Society for Neuroscience $\quad$ 0270-6474/03/235507-13\$15.00/0
}

development in the dorsal mesencephalon (Hynes et al., 1995a). The inductive effect of the floor plate can be mimicked by sonic hedgehog (Shh) (Hynes et al., 1995b) and blocked by antibodies against Shh (Ye et al., 1998). Inhibition of fibroblast growth factor 8 (FGF8) signaling by dominant negative FGF receptors prevents the development of DA neurons in mesencephalon and rostral diencephalon in explant cultures (Ye et al., 1998). These results suggested a combinatorial role for hedgehog $(\mathrm{Hh})$ and FGF8 signals in diencephalic and mesencephalic DA specification. However, the contributions of these as well as other potential signaling pathways have not been evaluated extensively in vivo.

Zebrafish is a model organism well suited for genetic analysis of CA system development, with a large number of available mutations affecting signaling pathways and the opportunity to perform forward genetic screens. During a mutagenesis screen, several mutants with abnormal tyrosine hydroxylase expression ( $\mathrm{TH}$; the rate-limiting enzyme in catecholamine biosynthesis) were isolated (Guo et al., 1999a). The analysis of the mutated genes confirmed findings on the role of Phox $2 \mathrm{a}$ in noradrenergic (NA) neuron development (Guo et al., 1999b) and also uncovered novel genetic components involved in DA differentiation, such as the transcription elongation factor Spt5 (Guo et al., 2000). The catecholaminergic system of adult zebrafish has been 
well studied (Ma, 1994a,b, 1997; Kaslin and Panula, 2001; Rink and Wullimann, 2001) and its development described in detail (Guo et al., 1999a; Holzschuh et al., 2001; Rink and Wullimann, 2002). Zebrafish CNS CA neuronal clusters corresponding to all mammalian CA neuronal groups have been identified, with the exception of the mesencephalic groups. In bony fish, DA neurons corresponding to the mesencephalic groups have not been detected in the midbrain (for review, see Meek, 1994; Smeets and Gonzalez, 2000). However, recent studies have provided evidence that some DA neurons in the zebrafish basal diencephalon have corresponding projection patterns and may be homologous to those of the mammalian mesencephalic substantia nigra (Kaslin and Panula, 2001; Rink and Wullimann, 2001). An analysis of the different times and locations at which DA neurons appear in the ventral diencephalon (Rink and Wullimann, 2002) led us to challenge the hypothesis of Hynes and Rosenthal (1999), that all DA neurons are specified close to places that are subject to a combination of FGF8 and Shh signaling.

Here, we investigate the influence of mutations affecting signaling pathways or centers that have been implicated previously in vertebrate CA development. We study the influence of mutations affecting Hh and FGF8 signaling as well as those affecting MHB development. Because Activin has been suggested to regulate TH expression in basal forebrain progenitors (Daadi et al., 1998), we analyzed the development of the CA system in mutations affecting transforming growth factor type $\beta$ (TGF $\beta$ )/Nodal signaling. Our findings point to differential requirements for the signaling input into the specification of the various CA groups: the pretectal and ventral diencephalic groups require Nodal signaling; the pretectal group also requires Shh signaling, as do the amacrine cells of the retina; and the locus coeruleus requires FGF8 signaling, whereas the CA neurons of the rhombencephalic medulla oblongata are not affected by mutations in any of these pathways.

\section{Materials and Methods}

Zebrafish maintenance and strains. Zebrafish were maintained under standard laboratory conditions at $28.5^{\circ} \mathrm{C}$ (Westerfield, 1995). Embryos were staged according to Kimmel et al. (1995) and fixed at the desired time points [age indicated as hours postfertilization (hpf) or days postfertilization (dpf)]. To avoid formation of melanin pigments, embryos were incubated in $0.2 \mathrm{~mm}$ 1-phenyl-2-thiourea (Sigma, St. Louis, MO). We used the following zebrafish mutations: acerebellar/fgf8 (ace $e^{\text {ti282a }}$ ) (Reifers et al., 1998), no isthmus/pax2.1 (noi ${ }^{\text {tu29a }}$ ) (Macdonald et al., 1997), spiel ohne grenzen/pou2 (spg ${ }^{\text {m793}}$ ) (Belting et al., 2001), one-eyed pinhead (oep ${ }^{\text {134 }}$ ) (Zhang et al., 1998), cyclops/ndr2 (cyc ${ }^{\text {b16 }}$ ) (Sampath et al., 1998), schmalspur/fast1 (sur ${ }^{m 768}$ ) (Pogoda et al., 2000; Sirotkin et al., 2000), sonic-you/shh $\left(s y u^{t 4}\right)$ (Schauerte et al., 1998), and slow muscle omitted/smoothened $\left(s m u^{b 641}\right)$ (Varga et al., 2001). Recently, during a new $N$-ethyl- $N$-nitrosourea (ENU) mutagenesis screen, we isolated a new smu allele $\left(s m u^{m 841}\right)$ (our observations) of similar allelic strength as $s m u^{b 641}$. In situ hybridization with th and dopamine transporter (dat) probes on $s m u^{m 841}$ and $s m u^{b 641}$ mutant embryos revealed that both alleles have identical phenotypes in DA neuron development (data not shown). Thus, we used $s m u^{m 841}$ mutants for our studies of DA neuron development.

In zebrafish, by the end of gastrulation, oep, cyc, squint (sqt; nodalrelated factor), and sur are expressed in the prechordal and posterior mesendoderm and later become restricted to the epiphysal region of the dorsal diencephalon during somitogenesis (Rebagliati et al., 1998; Sampath et al., 1998; Zhang et al., 1998; Concha et al., 2000; Pogoda et al., 2000; Sirotkin et al., 2000). Smads, mediators of TGF $\beta$ signaling, are expressed in several regions of the zebrafish brain including the hypothalamic and pretectal regions during early and late neuronal differentiation stages (Dick et al., 2000; Pogoda and Meyer, 2002).
Anatomical nomenclature. Zebrafish central CA neuronal clusters are named according to Guo et al. (1999a), Holzschuh et al. (2001), and Rink and Wullimann (2002). In these studies, correspondence between the following zebrafish and mammalian neuronal groups has been identified: caudal rhombencephalic groups [A1-A3; alpha numerical nomenclature of catecholaminergic cell groups originally proposed by Dahlström and Fuxe (1964); zebrafish medulla CA cluster first appearance, 36 hpf], rostral rhombencephalic groups (A4-A7; zebrafish locus coeruleus first appearance, $24 \mathrm{hpf}$ ), diencephalic groups [A11-A15; zebrafish ventral diencephalic CA clusters (ventral thalamus, posterior tuberculum, hypothalamus); first appearance, $20 \mathrm{hpf}$, olfactory bulb group (A16; zebrafish olfactory bulb cluster first appearance, $48 \mathrm{hpf}$ ), pretectal group (first appearance, $60 \mathrm{hpf}$ ), and hypothalamic paraventricular organs. DA neurons corresponding to the mesencephalic groups (A8-A10 in mammals) have not been detected in the zebrafish midbrain. However, there is strong evidence that subgroups of basal diencephalic DA neurons in the zebrafish are homologous to some of the A8-A10 dopaminergic neurons of higher vertebrates (Kaslin and Panula, 2001; Rink and Wullimann, 2001, 2002). In addition, from $60 \mathrm{hpf}$ on, amacrine th-expressing cells can be detected in the zebrafish retina. On day 5 of development, subpallial and preoptic CA groups can be identified (Rink and Wullimann, 2002). However, in the current analysis, we do not distinguish these groups because, based on the abnormal mutant morphologies, their identification was not possible for several of the mutations analyzed.

Whole-mount in situ hybridization. Standard methods for wholemount in situ hybridization were used (Hauptmann and Gerster, 1994) with th, dat (Holzschuh et al., 2001), pax6.1 (Krauss et al., 1991), hlx1/ dbx1a (Fjose et al., 1994), dlx2 (Akimenko et al., 1994), axial/foxa2 (Strähle et al., 1996), and shh (Krauss et al., 1993) antisense RNA probes.

\section{Results}

\section{The first dopaminergic neurons in zebrafish differentiate} along the alar-basal boundary of the posterior tuberculum

To better understand the specific signaling environment in which the various CA neuronal groups develop, we determined where these neurons differentiate relative to developmental boundaries and signaling centers. In the early embryonic zebrafish brain, few morphological landmarks exist to determine the exact location of neuronal groups. Thus, we used the expression domains of regulatory genes known to subdivide the embryonic forebrain as topological markers (Macdonald et al., 1994; Rubenstein and Beachy, 1998; Hauptmann and Gerster, 2000): pax6.1, hlx1/ $d b x 1 a, d l x 2$, axial/foxa2, and shh. We used expression of th as a marker for catecholaminergic differentiation. The first DA neurons arise within and anterior to the most rostral transverse $h l x 1 /$ $d b x 1 a$ expression domain (Fig. $1 A$ ). These neurons differentiate along the ventral limit of the longitudinal $d l \times 2$ domain (Fig. $1 B$ ) and the ventral thalamic pax6.1 domain (Fig. 1D) (Wullimann and Rink, 2001), delimited posterior by the anterior end of the longitudinal expression domain of axial/foxa2 (Fig. 1C). The first DA neurons differentiate in a region of the ventroanterior diencephalon in which shh expression is downregulated by $24 \mathrm{hpf}$ (Fig. $1 E$ ). The most dorsal expression domain of $h l x 1 / d b x 1 a$ corresponds to the dorsal-most part of the pretectum (Hauptmann and Gerster, 2000), and is the region in which pretectal DA-CA neurons differentiate in zebrafish from $60 \mathrm{hpf}$ onwards (Fig. 1A) (Holzschuh et al., 2001). Our analysis reveals that the first DA neurons differentiate close to the proposed alar-basal boundary in the posterior tuberculum, a brain area that is supposed to form the basal part of prosomere 3 (p3) (Hauptmann and Gerster, 2000; Rink and Wullimann, 2002).

\section{FGF8 signaling is not required for differentiation of the first dopaminergic neurons}

Previous studies showed that FGF8-soaked beads can induce differentiation of DA neurons in explant cultures from embryonic 

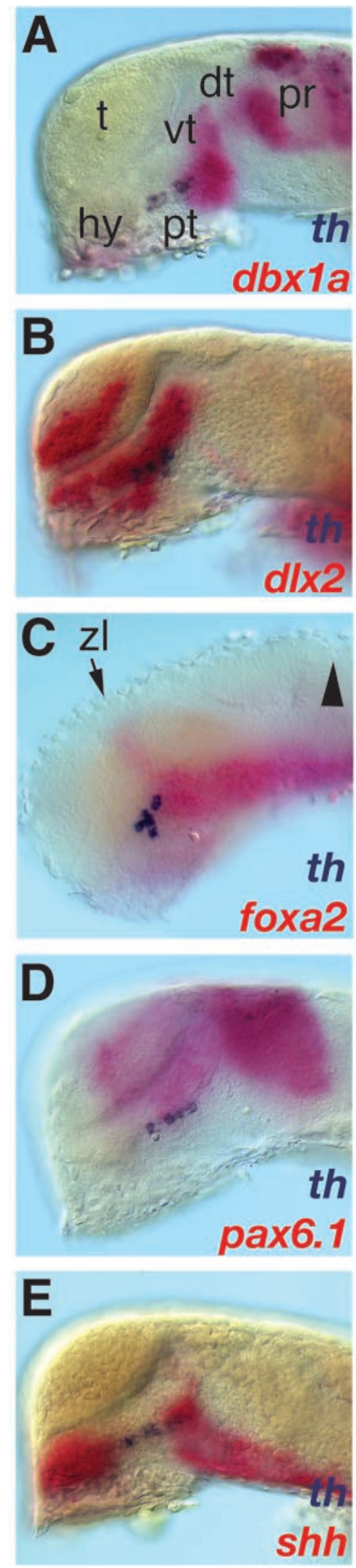

Figure 1. The first dopaminergic neurons differentiate in the diencephalic posterior tuberculum. Visualization of forebrain gene expression domains and th expression by double in situ hybridization of whole-mount wild-type embryos are shown. $A-E$, Lateral views of the brain (anterior is to the left, dorsal is to the top). In situ hybridization of $24 \mathrm{hpf}$ embryos with $d b x 1 a$ $(A), d 1 \times 2(B)$, foxa1 $(C)$, pax6.1 $(D)$, and shh $(E)$ is shown in red, and th is in blue. For better rat brain, whereas DA differentiation can be prevented by introducing dominant-negative FGF receptors (Ye et al., 1998). To determine whether FGF8 is also required for differentiation of DA neurons in zebrafish, we analyzed DA development in $f g f 8 /$ ace $\left(\right.$ ace $\left.^{t i 282 a}\right)$ (Reifers et al., 1998) mutant embryos. Whereas ace/fgf 8 mutants fail to develop the MHB and cerebellum, the more anterior and posterior brain regions are less affected (Brand et al., 1996; Reifers et al., 1998). In ace mutant embryos, the earliest differentiating DA neurons appear in the posterior tuberculum between 20 and $24 \mathrm{hpf}$ in normal position and number (Fig. $2 A, B$ ). However, at $3 \mathrm{dpf}$, ace mutant embryos lack the most anterior DA neurons in the posterior tuberculum (Fig. 2C,D). Furthermore, the cluster of th-expressing cells located in rhombomere 1 (locus coeruleus) (Fig. 2 E, F) is absent in ace mutants at $3 \mathrm{dpf}$, consistent with the results obtained by Guo et al. (1999b) for earlier stages. However, CA neurons in the olfactory bulb, (Fig. $2 G, H$ ), pretectum, medulla oblongata, and amacrine cells of the retina appear normal in ace mutants (Table 1; data not shown). We then investigated whether overexpression of $f g f 8$ mRNA by injection into one-cell stage embryos can affect DA development. Overexpression of FGF8 at high levels (60 or 100 pg $f g f 8$ mRNA per embryo) results in a range of early patterning defects, including expansion of dorsolateral derivatives at the expense of ventral and posterior fates during gastrulation (Furthauer et al., 1997), which makes it impossible to identify specific effects on DA development. Injection of $f g f 8$ mRNA at lower concentrations ( $30 \mathrm{pg}$ per embryo) that do not affect early patterning also has no effect on DA neuron development (data not shown). Application of FGF beads may induce an additional MHB organizer in the diencephalon (Liu et al., 1999). Thus, whereas the lack-of-function ace phenotype indicates a role of FGF8 in NA neuron development in the locus coeruleus (LC), in vivo gain-of-function experiments have been less informative.

The only other characterized member of the FGF8/17/18 subgroup of Fgfs in zebrafish is an ortholog to mammalian Fgfl7. Zebrafish $f g f 17$ is coexpressed with $f g f 8$ in the MHB from approximately the 8-somite stage onwards (Reifers et al., 2000). We therefore studied th and dat expression in zebrafish embryos mutant for no isthmus/pax2.1, which do not form the MHB or express fgf17 (Brand et al., 1996; Lun and Brand, 1998; Reifers et al., 2000). In noi mutant embryos, the DA neurons in the posterior tuberculum appear normal at $24 \mathrm{hpf}$ (Table 1; data not shown) but are slightly reduced in number at $48 \mathrm{hpf}($ Fig. $3 A-D)$. The olfactory bulb and pretectal DA, as well as medulla oblongata NA neurons, are not affected in noi mutant embryos (Fig. $3 E-H$, Table 1; data not shown). In contrast, locus coeruleus CA neurons are missing at $3 \mathrm{dpf}$ in noi mutants (Fig. $3 F, H$ ), as described for earlier stages (Guo et al., 1999b).

To reveal possible redundant functions of FGF8 and FGF17, we analyzed th and dat expression in ace noi double mutant embryos that lack expression of both FGF8 and FGF17 (data not shown). Among 100 progeny from an intercross of ace noi double

\footnotetext{
visibility, the skin, eyes, and yolk have been removed except in C where only the yolk has been removed. $A$, The ventral part of the most anterior transverse $d b x 1 a$ expression domain marks the caudal hypothalamus. $B$, The DA neurons are located within the $d / x 2$ expression domain in the hypothalamus. $C$, The DA cluster extends caudally to the anterior end of the longitudinal expression domain of foxa2 (arrowhead indicates the midbrain-hindbrain boundary). D, The DA cluster extends longitudinally close to the ventral edge of the alar plate (ventral border of $p a x$ 6.1 expression) in the basal plate marked by the shh expression domain (E). dt, Dorsal thalamus; hy, hypothalamus; pr, pretectum; pt, posterior tuberculum; $t$, telencephalon; vt, ventral thalamus; zl, zona limitans intrathalamica.
} 


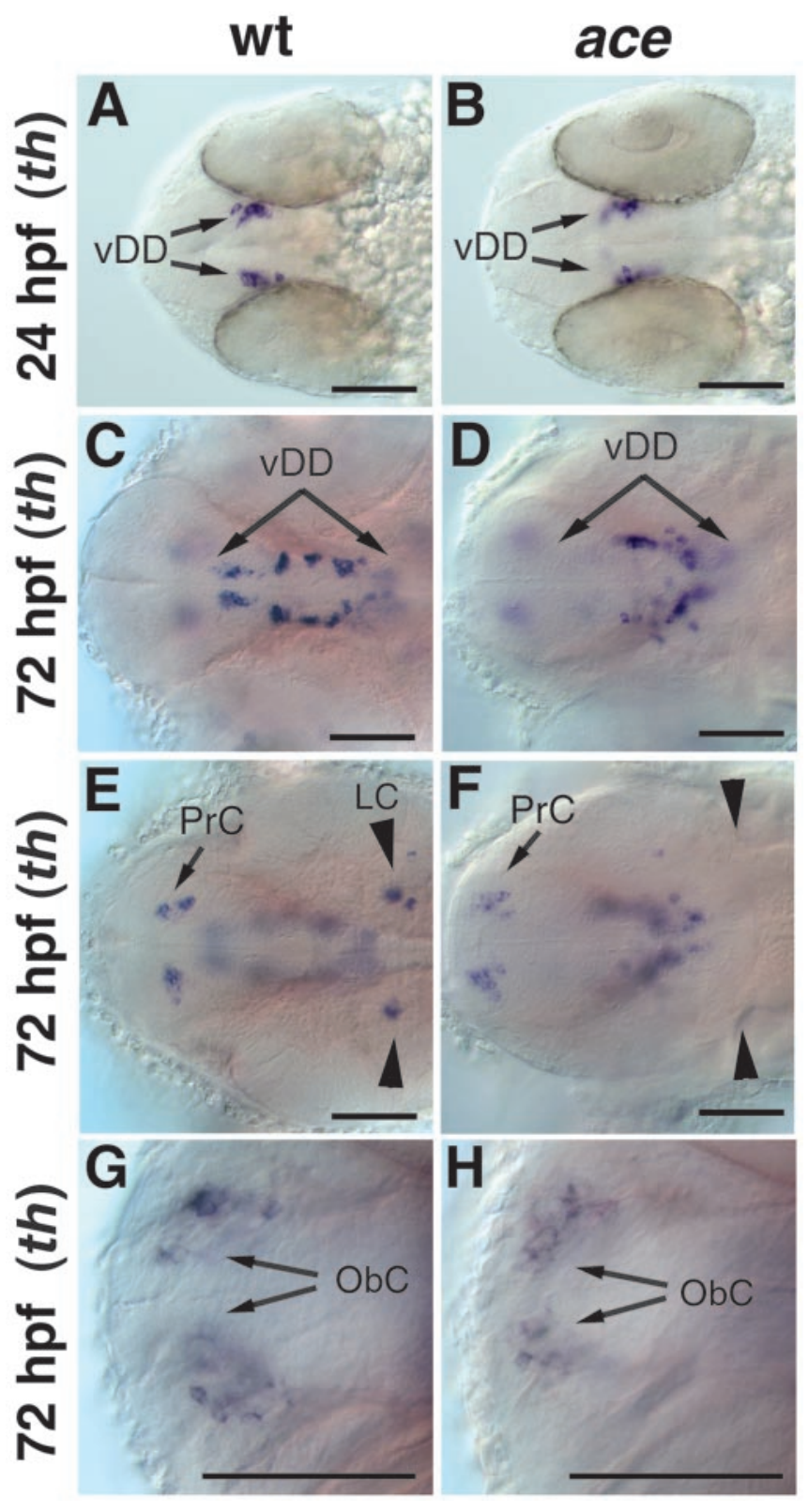

Figure 2. Formation of dopaminergic groups is not affected in ace/fgf8 mutant embryos. $A-H$, Whole-mount in situ hybridization for th expression in wild-type $(A, C, E, G)$ and ace mutant embryos $(B, D, F, H) . A-H$, Dorsal views; anterior is to the left. $A, B$, The first th-expressing dopaminergic neurons appear normal in ace mutants at $24 \mathrm{hpf}$. C, D, At $72 \mathrm{hpf}$, fewer dopaminergic neurons are seen in the ventral diencephalon of ace mutants compared with that of wild-type embryos, whereas th expression appears normal in the pretectum and olfactory bulbs $(E-H) . E, F$, The noradrenergic neurons of the $\mathrm{LC}$ are absent in ace mutants. vDD, Ventral diencephalic dopaminergic neurons; $\mathrm{ObC}$, olfactory bulb catecholaminergic neurons; $\mathrm{PrC}$, pretectal catecholaminergic neurons. Scale bars, $50 \mu \mathrm{m}$.

heterozygous fish, we found none with a CA phenotype more severe than that of ace or noi single mutant embryos; all progeny developed DAT-expressing cells in the ventral diencephalon, pretectum, and olfactory bulb. Thus, our results indicate that FGF8 and FGF17 are not strictly required for DA neuron formation in the forebrain and do not act redundantly in this process. In contrast, our results confirm a requirement for FGF8 during CA neuron development in the locus coeruleus.

Although both noi and ace mutants fail to maintain the MHB organizer, these mutations do not affect its initial establishment.
To elucidate potential early roles of the MHB in CA system development, we analyzed spiel ohne grenzen mutant embryos, which fail to establish the MHB. spg is required early during MHB establishment and encodes the zebrafish pou 2 gene (Belting et al., 2001; Burgess et al., 2002). In spg mutant embryos at $3 \mathrm{dpf}$, the CA neurons of the locus coeruleus are absent, whereas the number of DA neurons is only slightly reduced in the ventral diencephalon (Fig. $4 A, B$ ). The CA groups of the pretectum, olfactory bulb, medulla oblongata, and area postrema are not affected (Fig. $4 C-F$, data not shown).

POU domain proteins have been implicated in catecholaminergic and serotonergic neuronal differentiation in invertebrates (Johnson and Hirsh, 1990; for review, see Twyman and Jones, 1995). However, zebrafish spg/pou 2 may predominantly act in midbrain and hindbrain patterning rather than in neural differentiation as expression of pou2 in the brain ceases at approximately the 5-somite stage, long before CA neuron differentiation (Hauptmann and Gerster 1995; Belting et al., 2001).

\section{Shh is required for DA neuron development in the} diencephalic alar plate but not in the basal plate

We investigated whether lack of Shh signaling can affect DA neuron differentiation in zebrafish mutants. The zebrafish syu locus encodes the ortholog of the mammalian Shh gene (Schauerte et al., 1998). Although syu mutant embryos fail to form lateral floor plate cells and have defects in somite patterning, early forebrain development appears morphologically fairly normal (Schauerte et al., 1998; Odenthal et al., 2000). During early dopaminergic neuron differentiation (18-24 hpf), DA cell clusters appear normal in syu mutants (data not shown). Later in development (3 $\mathrm{dpf}$ ), analysis of th expression reveals that the pretectal cluster of catecholaminergic neurons is reduced or even absent in syu mutants (Fig. $5 A, C, E$ ). In addition, the morphology of the ventral diencephalic DA clusters is disturbed, and the number of neurons is reduced. In contrast, the DA neurons in the olfactory bulb and the CA neurons in the LC and medulla oblongata are not affected in syu mutant embryos (Fig. 5C,E; data not shown).

Two additional hedgehog genes exist in zebrafish, tiggy-winkle hedgehog (tww) (Ekker et al., 1995) and echidna hedgehog (ehh) (Currie and Ingham, 1996). The relatively mild DA phenotype in syu mutants could be attributable to redundant functions of these hedgehog genes. To address this issue, we analyzed mutant embryos that are unable to transduce Hh signals. The zebrafish locus smu encodes the transmembrane Hh signal transducer Smoothened (Smoh) (Chen et al., 2001; Varga et al., 2001). Because Smoh is necessary to transduce all Hh signaling into the cell, we can use the smu mutation to test whether Hh signaling is required for specification of DA neurons. In smu mutant embryos, the ventral hypothalamic dopaminergic neurons in the posterior tuberculum first appear at a similar stage, as do those in wild-type embryos, as judged from dat expression at $24 \mathrm{hpf}$ (Fig. 6C). However, by $48 \mathrm{hpf}, \mathrm{DA}$ neurons in smu mutants are located in a domain of dorsoventral orientation, compared with the anterioposterior orientation in wild-type embryos (Fig. $6 B, D$ ). This may be because of other morphological changes, including changes in cell migration, occurring in smu mutants. Similar to that in syu mutants, the pretectal cluster of CA neurons in smu mutants is either absent or reduced (Fig. 5G,I), corroborating the idea that Hh signaling is required for DA development in the pretectum.

In the retinae of both syu and smu mutants, dat-expressing amacrine cells are absent or reduced in number, indicating a defect in DA amacrine cell differentiation (Fig. 5D, F, H,J). The absence of dat-expressing reticular astrocytes surrounding the 
Table 1. Effects of hedgehog, FGF8, and Nodal pathway mutants on the formation of the main dopaminergic and noradrenergic groups in the zebrafish CNS

\begin{tabular}{|c|c|c|c|c|c|c|c|c|c|c|c|}
\hline & \multicolumn{4}{|c|}{ Nodal signaling } & \multicolumn{2}{|c|}{ Hh signaling } & \multirow{2}{*}{$\frac{\text { Hh plus FGF8 }}{\text { smu/ace }}$} & \multicolumn{4}{|c|}{ MHB organizer-FGF8 } \\
\hline & MZsur & Zsur & oep & $c y c$ & syu & smu & & ace & spg & noi & ace/no \\
\hline \multicolumn{12}{|c|}{ Ventral diencephalic DA neurons } \\
\hline $24 \mathrm{hpf}$ & - & $(+)$ & (0) & $(0)$ & + & + & + & + & $(+)$ & + & $(+)$ \\
\hline $48 \mathrm{hpf}$ & - & $(-)$ & (0) & (0) & \#/- & $\#$ & $\#$ & - & $(+)$ & - & $(-)$ \\
\hline $72 \mathrm{hpf}$ & N.D. & - & 0 & 0 & $\# /-$ & $\# /-$ & N.D. & + & - & + & $(-)$ \\
\hline \multicolumn{12}{|c|}{ Pretectal CA neurons } \\
\hline $72 \mathrm{hpf}$ & N.D. & + & 0 & 0 & -10 & -10 & N.D. & + & $(+)$ & + & $(+)$ \\
\hline \multicolumn{12}{|c|}{ Locus coeruleus CA neurons } \\
\hline $48 \mathrm{hpf}$ & N.D. & + & $(+)$ & $(+)$ & $(+)$ & $(+)$ & 0 & 0 & (0) & 0 & (0) \\
\hline $72 \mathrm{hpf}$ & N.D. & + & + & + & $(+)$ & $(+)$ & N.D. & 0 & 0 & 0 & (0) \\
\hline \multicolumn{12}{|c|}{ Medulla oblongata CA neurons } \\
\hline $48 \mathrm{hpf}$ & N.D. & $(+)$ & $(+)$ & $(+)$ & $(+)$ & $(+)$ & $(+)$ & + & $(+)$ & + & $(+)$ \\
\hline $72 \mathrm{hpf}$ & N.D. & $(+)$ & + & + & $(+)$ & $(+)$ & N.D. & + & + & + & $(+)$ \\
\hline \multicolumn{12}{|c|}{ Amacrine DA neurons } \\
\hline $72 \mathrm{hpf}$ & N.D. & $(+)$ & + & 0 & -10 & -10 & N.D. & + & $(+)$ & N.D. & N.D. \\
\hline \multicolumn{12}{|c|}{ Olfactory bulb CA neurons } \\
\hline $72 \mathrm{hpf}$ & N.D. & + & 0 & $-/ 0$ & + & + & N.D. & + & + & + & + \\
\hline
\end{tabular}

,+ Not affected; - , reduced; 0 , absent; - /0, highly reduced or absent; \#, altered morphology of the neuronal cluster; N.D., not determined; symbols in brackets, data not shown in figures; hpf, hours postfertilization.

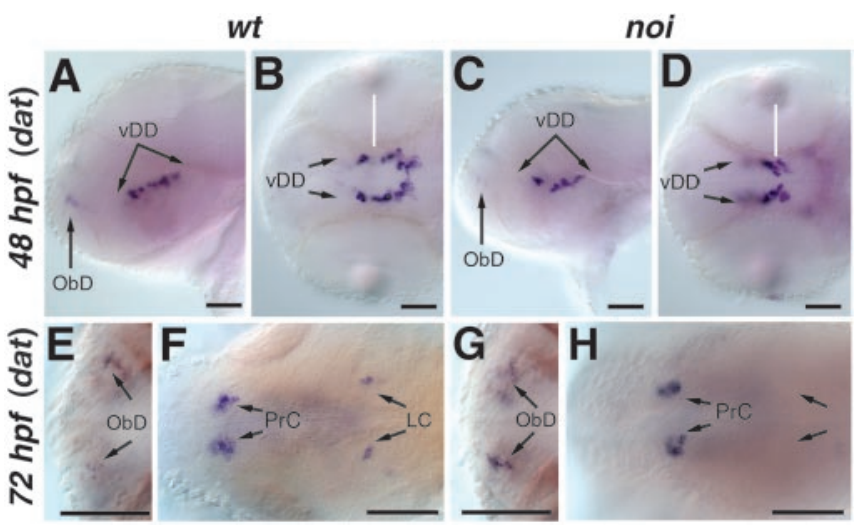

Figure 3. The $\mathrm{LC}$ is absent and the ventral diencephalic dopaminergic neurons are slightly reduced in noi/pax2.1 mutant embryos. Whole-mount in situ hybridization for dat in wild-type $(A, B, E, F)$ and noi/pax2.1 $(C, D, G, H)$ mutant embryos. $A, C$, Lateral views, dorsal is to the top. $B$, $D, E-H$, Dorsal views, anterior is to the left. $A-D, A t 48 \mathrm{hpf}$, the dat expression pattern reveals a slight decrease in ventral diencephalic dopaminergic neurons in noi mutant embryos. $E-H$, The catecholaminergic neurons in the olfactory bulb and pretectum appear normal in noi mutant embryos. $F, H, I n$ noi mutant embryos, the $L C$ is absent. vDD, Ventral diencephalic dopaminergic neurons; ObD, olfactory bulb catecholaminergic neurons; $\mathrm{PrC}$, pretectal catecholaminergic neurons. Scale bars, $30 \mu \mathrm{m}$.

optic nerve in these mutants indicates that the development of these cells also depends on Hh signaling (Fig. $5 \mathrm{H}, \mathrm{J}$ ).

\section{shh and $f g f 8$ double mutants do not reveal synergistic effects in DA system development}

Our analysis of syu/shh, smu/smoh, and ace/fgf 8 mutant embryos reveals that DA neurons successfully develop in the diencephalon in the absence of either Shh or FGF8 signaling. To examine whether these two signaling pathways interact to specify DA neurons, we generated double mutants for smu and ace and examined the expression of th and dat. The expression of dat in the ventral diencephalon of smu ace double mutants at $24 \mathrm{hpf}$ is similar to that in wild-type embryos (Fig. 6A,G). By $2 \mathrm{dpf}$, we detected changes in th expression in smu ace double mutants, which are additive with respect to the single mutant phenotypes of smu or ace (Fig. $6 B, D, F, H$ ). The smu ace double mutants lack the locus coeruleus, as do ace mutants, and show an altered morphology in the ventral diencephalic DA cluster, as do smu mutants. By $3 \mathrm{dpf}$, the smu ace double mutants have begun to degenerate, preventing additional investigation of DA system development. Together, our data indicate that the earliest differentiation of ventral diencephalic DA neurons (20-40 hpf) does not depend on either Hh or Fgf8 signaling alone, or in combination.

\section{Differentiation of CA neurons of the basal and alar plate is affected in Nodal pathway mutants}

A subset of dopaminergic neurons in C. elegans depends on a functional TGF $\beta$-signaling pathway (Lints and Emmons, 1999) and is absent in dbll mutants. dbll encodes a Nodal-related TGF $\beta$ signal (Morita et al., 1999; Newfeld et al., 1999; Suzuki et al., 1999). To explore a potential role of Nodal signaling in CA development, we analyzed the CA system in zebrafish Nodal pathway mutants.

cyc encodes the Nodal-related protein Ndr2 (Rebagliati et al., 1998; Sampath et al., 1998). Embryos homozygous mutant for the $c y c^{b 16}$ allele, a deletion including the $c y c$ locus, lack the floor plate and have a single fused cyclopic eye resulting from the absence of ventral forebrain tissue (Hatta et al., 1991; Varga et al., 1999). In cyc mutant embryos, the diencephalic CA neurons of the pretectum and posterior tuberculum are absent, and few neurons in the region of the olfactory bulb are present. The catecholaminergic cell clusters in the hindbrain form in $c y c$ mutants but are not well patterned, and the retinal DA amacrine cells are reduced (Fig. $7 A, B$; data not shown).

The zebrafish membrane-bound EGF-CFC (epidermal growth factor-Cripto, Frl-1, and Cryptic family member) protein Oep is required for the reception of Nodal signals (Zhang et al., 1998; Gritsman et al., 1999). In oep mutant embryos, all forebrain CA clusters are absent (Fig. $7 C$ ) while the CA neurons in the hindbrain (locus coeruleus and medulla clusters) develop, and the DA amacrine cells are not affected (Fig. 7C,D; data not shown).

The zebrafish transcription factor Sur/FoxH1/Fast1 is a nuclear signal transducer for Nodal signaling (Pogoda et al., 2000; Sirotkin et al., 2000). Maternal and zygotic (MZ) sur homozygous mutants lack all FoxH1/Fast1 activity. In MZsur, the ventral diencephalic CA neurons are often completely absent, whereas the CA neurons of the locus coeruleus appear unaffected (Fig. 7E). In contrast, zygotic (Z) sur mutants develop a reduced number of DA neurons in the basal diencephalic region (Fig. $8 A, B, G-J$ ). In Zsur mutants, the pretectal DA neurons are either not affected or 
only slightly reduced (Fig. $8 E, F$ ), whereas no alteration in thexpression is seen in the olfactory bulbs (Fig. 8C,D) or locus coeruleus (Fig. 8G,H).

Together, these findings indicate that the Nodal pathway is not only required for the early establishment of the hypothalamus (Varga et al., 1999; Rohr et al., 2001; Mathieu et al., 2002) but also for the formation of DA neurons in the remainder of the forebrain. Nodal pathway mutants lack diencephalic DA neurons of the basal plate (posterior tuberculum and hypothalamus) as well as the alar plate (thalamus and pretectal cluster).

\section{Nodal and Hh pathway mutants affect early patterning of the ventral forebrain but not the pretectum}

The pretectal and hypothalamic CA system defects in $\mathrm{Hh}$ and Nodal signaling pathway mutants could be caused either indirectly by early patterning defects that prevent development of the respective brain regions, or by a more direct involvement of $\mathrm{Hh}$ and Nodal signaling in CA neuron specification. To distinguish between these possibilities, we investigated forebrain patterning in these mutants by visualizing region-specific expression domains of $h l \times 1 / d b \times 1 a, d l \times 2$, and $s h h$ at $24 \mathrm{hpf}$, the time of CA neuron formation.

In MZ sur mutants, $d l x 2$ and shh are expressed in the diencephalon, but the most anterior domains of expression are lost. The remaining domains enclose the posterior tuberculum in which DA neurons differentiate (Fig. 9D,E). The $h l \times 1 / d b x 1 a$ domains in the posterior tuberculum and the pretectum are unchanged (Fig. 9C,F). In contrast, in the more severe Nodal pathway mutants oep and $c y c$, the hypothalamic expression domains of $h l \times 1 / d b x 1 a, d l x 2$, and shh do not form (Fig. 9G-L), whereas $h l \times 1 / d b x 1 a$ expression does occur in the pretectum (Fig. 9I,L).

smu mutants show no shh expression in the zona limitans with reduced expression in the midline (Fig. 9M). The expression domain of $d l \times 2$ that marks the anterior boundary of prosomere 3 is present in smu mutants (Fig. 9N) (Varga et al., 2001). The dlx2 expression domain in the telencephalon is enlarged, whereas the dorsal domains of $d l x 2$ expression in the diencephalon are reduced (Fig. 9N). The expression domain of $h l \times 1 / d b \times 1 a$ in the dorsal pretectum appears normal in smu mutants (Fig. 9O).

The expression domains of $h l x 1 / d b x 1 a$ are expanded ventrally into the basal plate in both Nodal pathway and smu mutant embryos (Fig. 9C, F, $I, L, O$ ), consistent with the dorsal-ventral patterning defects in those mutants. Interestingly, in Mzsur, oep, and $c y c$ mutants, the $h l \times 1 / d b x 1 a$ domain is also expanded in the dorsal midbrain. A summary of the early neural patterning defects correlated with the neuronal phenotype in Nodal pathway mutants is provided in Table 2 .

Our analysis of pattern formation in the CNS of mutant embryos indicates that the pretectum develops normally in Nodal and Hh pathway mutants. We can then exclude the possibility that the defects in CA neuron specification in the pretectum are caused indirectly by early patterning defects and subsequent loss of the pretectum. In addition, the expression domains of $s h$, $d l x 2$, and $h l x 1 / d b x 1 a$ observed in the hypothalamic region of $\mathrm{Mz}$ sur mutant embryos indicate that the diencephalic territories in which DA neurons normally would form are present in the mutant embryos. Thus, Nodal signaling may also be directly involved in DA neuron differentiation in the ventral diencephalon.

\section{Discussion}

It has been hypothesized that, in mammals, all DA neuron progenitors arise from two regions, the telencephalic and diencephalic area near the anterior neural ridge (ANR) and the midbrain, rostral to the $\mathrm{MHB}$ and that all of these progenitors depend on Shh signaling from the midline and Fgf8 signaling from the MHB and ANR (Hynes and Rosenthal, 1999). This unifying hypothesis does not reflect our experimental data in zebrafish. In fish, the DA neurons of the olfactory bulbs, pretectum, ventral diencephalon, and other regions develop in several distinct locations, and, thus, are likely exposed to different combinations of developmental signals and yet still develop the same DA neurotransmitter phenotype. Later in development, DA neurons in different clusters vary significantly in their neuronal properties and projection behavior. Thus, the ability of a neurectodermal cell to react or not to a given signal to achieve CA fate likely depends on both its prepattern as well as its environment, and the combination of signals experienced during development will determine its neuronal subtype and projection behavior. Our genetic analysis distinguishes contributions of individual signaling pathways to CA specification (summarized in Table 1): the pretectal and ventral diencephalic groups require Nodal signaling, the pretectal group and amacrine cells of the retina require Shh signaling, and the locus coeruleus requires signals from the $\mathrm{MHB}$ including FGF8, whereas the CA neurons of the rhombencephalic medulla oblongata are not affected by mutations in any of these pathways. Of the mutants analyzed, the DA neurons of the 

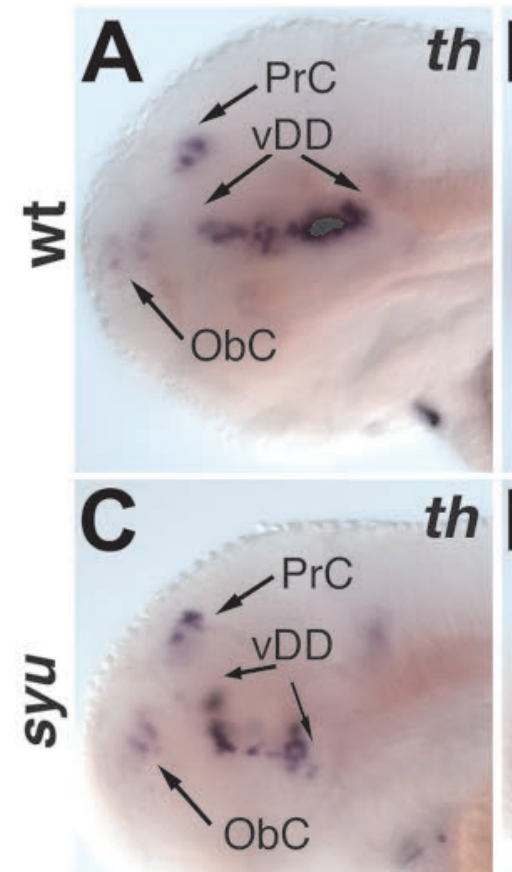

th

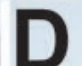

th
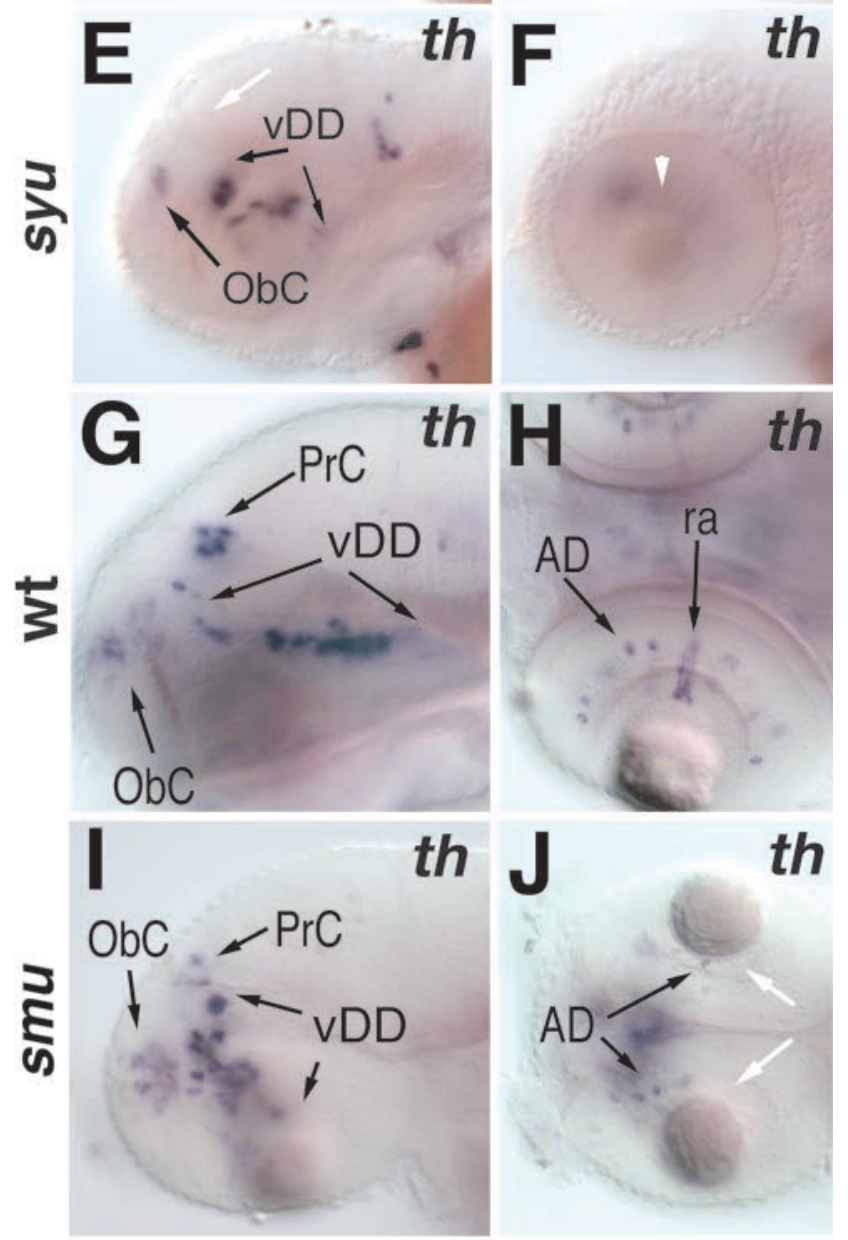

Figure 5. The pretectal catecholaminergic neurons and the amacrine cells of the retina are affected in hedgehog pathway mutants. $A-F$, th expression at $3 \mathrm{dpf}$ in wild-type $(A, B)$ and syu $(C-F)$ mutant embryos (lateral views, anterior is to the left, dorsal is to the top). $A, C, E$, The pretectal cluster of catecholaminergic neurons is reduced $(C)$ or absent $(E$, white arrow) in syu mutant embryos. The dopaminergic cell cluster in the ventral diencephalon is altered in

\section{4 hpf dat 48 hpf th}
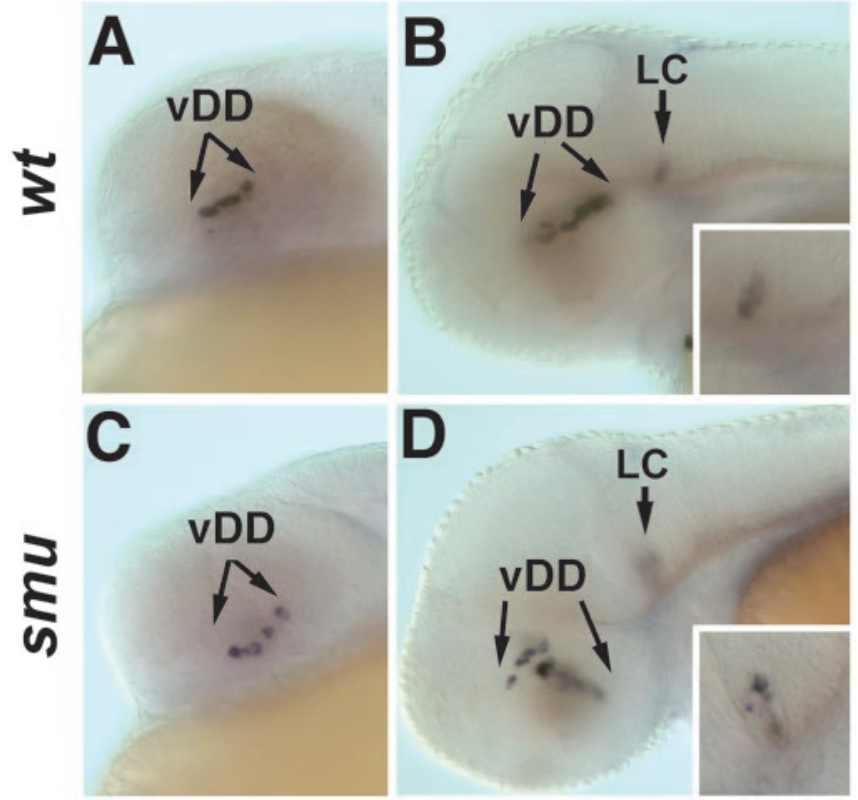

$\mathbf{E}$
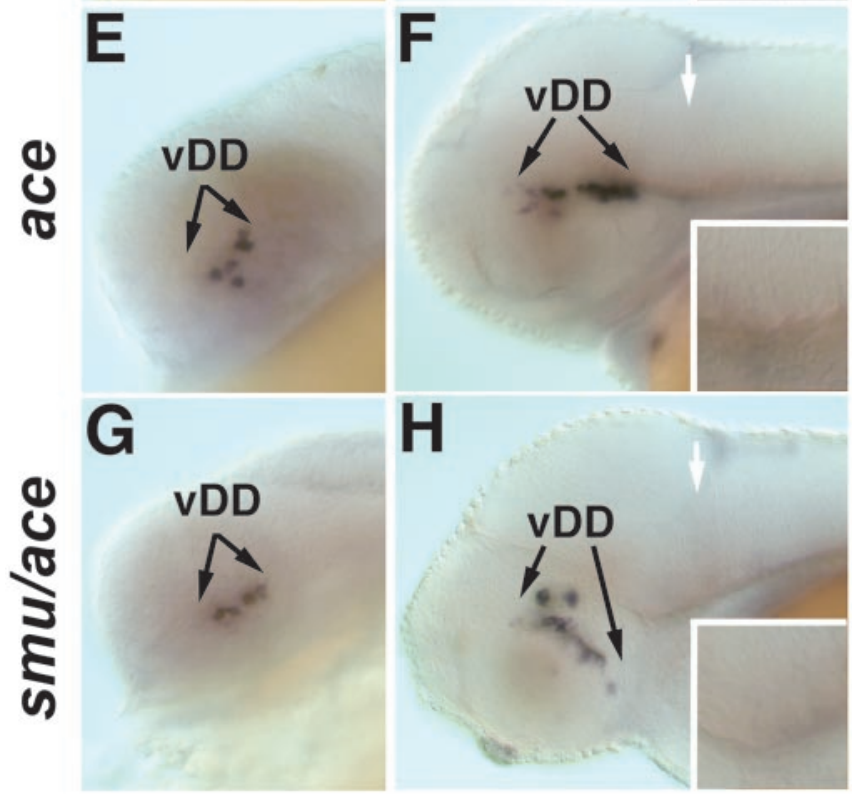

Figure 6. smu/smoh and ace/fgf8 double mutants develop additive DA neuronal phenotypes. $A, C, E, G$, dat expression or th expression $(B, D, F, H) . A-H$, Lateral views, anterior to the left, dorsal is to the top. In $s m u / s m o h(C)$, ace/fgf8 $(E)$, and smu ace $(G)$ double mutants, the earliest developing dopaminergic neurons in the ventral diencephalon appear normal when compared with wild-type embryos ( $A)$. By $48 \mathrm{hpf}$, additive phenotypes are observed in smu ace double mutants $(H)$; the ventral diencephalic cluster is misshapen as in smu mutants $(D)$ and the $\mathrm{LC}$ is absent as in ace $(F)$. Insets in $B, D, F$, and $H$ show higher magnification views of the region of the locus coeruleus. vDD, Ventral diencephalic dopaminergic neurons. White arrows indicate the absence of the $\mathrm{LC}$.

$\leftarrow$

morphology but not in size in syu mutant embryos. $D, F$, Dopaminergic amacrine cells are reduced $(D)$ or absent $(F$, white arrowhead) in syu mutant embryos. $G-J$, dopamine transporter expression in 3 dpf embryos. $G-J$, Lateral views $(G, I)$ and dorsal views $(H, J)$; anterior is to the left. $G, I, 0$ f the CNS dopaminergic clusters, only the pretectal cluster is affected in smu mutants. $H, J$, The dopaminergic amacrine cells are reduced and the dat-expressing reticular astrocytes are absent in smu mutant embryos (J, white arrows). AD, Amacrine dopaminergic neurons; VDD, ventral diencephalic dopaminergic neurons; $\mathrm{ObC}$, olfactory bulb catecholaminergic neurons; PrC, pretectal catecholaminergic neurons. 


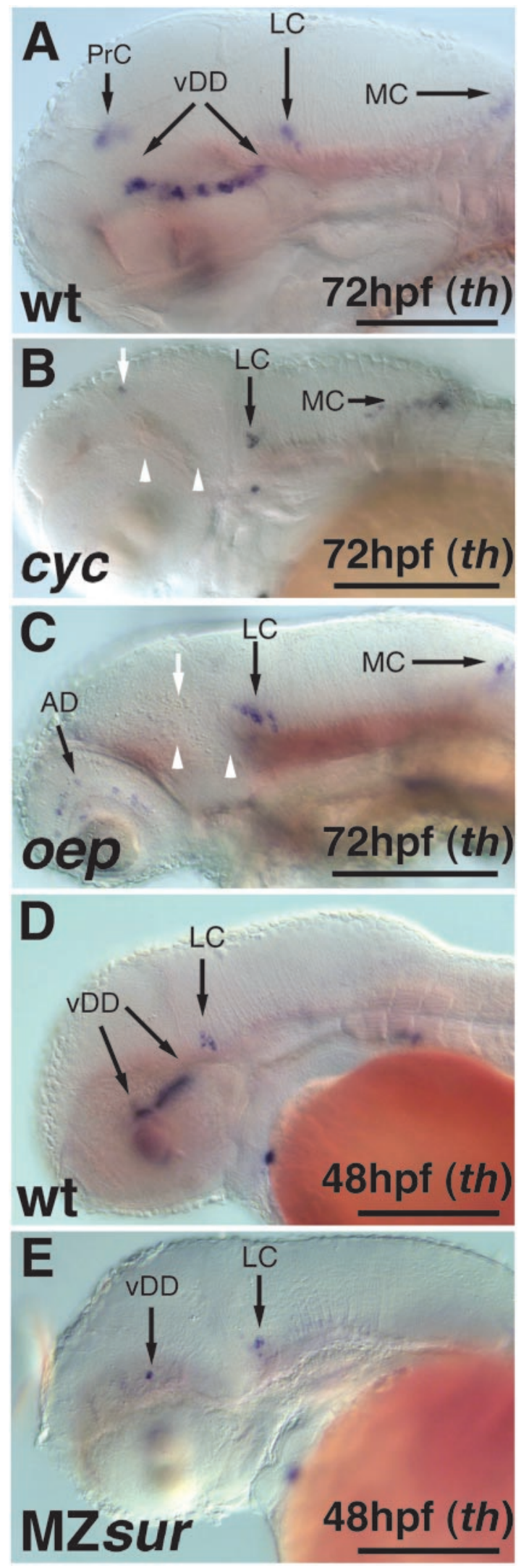

Figure 7. Nodal pathway mutants affect the development of the ventral diencephalic and pretectal catecholaminergic neurons. $A-E$, th expression revealing the effects of mutations within the Nodal pathway on catecholaminergic neuron development (lateral views, anterior is to the left). $A, D$, th expression in wild-type embryos at 72 and $48 \mathrm{hpf}$, respectively. $B$, In cyc mutant embryos, both the ventral diencephalic DA neurons and the catecholaminergic neurons of the pretectum fail to develop, whereas the $C A$ neurons in olfactory bulb are absent only in Nodal pathway mutants, which show absence of most or all of the olfactory tissue. Thus, olfactory DA neurons may not directly respond to Nodal signaling.

\section{FGF8 and the MHB are not strictly required for DA neuron differentiation in zebrafish}

A role of FGF8 and Shh in regulating DA cell specification was postulated, primarily on the basis of experiments using cell and explant cultures of chicken, mouse, and rat brains (Hynes et al., 1995a; Wang et al., 1995; Ye et al., 1998; Lee et al., 2000). Although both shh and FGF8 mutant mice have been generated, difficulties in analyzing the appropriate stages in mutant mice have prohibited thorough investigation of the potential roles of these signals during DA cell specification. In contrast, zebrafish mutant for $f g f 8$, shh, and/or smu/smoothened proceed in their development to stages in which DA differentiation can be investigated. In the zebrafish ace/fgf8 mutant, as well as in ace smu double mutants, both the formation of DA neurons near the ANR in the olfactory bulbs and the initiation of ventral diencephalic DA differentiation appear normal. At later developmental stages, the slight reduction in the number of DA neurons could be caused by secondary effects such as patterning abnormalities. Likewise, in noi/pax2.1 and spg/pou 2 mutant embryos, which lack the MHB, ventral diencephalic DA neurons are reduced in number only at later stages. Together, this implies that the absence of the MHB organizer may result in lessened production of proliferation or survival signals. Because the MHB is much further from the ventral diencephalon when the first DA neurons differentiate, it is unlikely that the MHB provides inductive, proliferative, or survival signals to these neurons at this stage.

Both in vivo and in vitro analyses of mammalian brain development also support the conclusion that Fgf8 and Shh are not required for DA neuronal fate specification. The $\mathrm{MHB}$, the source of FGF8 suggested to be important for midbrain DA neuronal development, is absent in engrailed-1 mutant mice (Wurst et al., 1994), in which the midbrain DA neurons initially form but later disintegrate (Simon et al., 2001). Immortalized rat mesencephalic cells, which produce neither Shh nor Fgf8, are still able when added as a feeder layer to significantly increase the number of TH-positive neurons in rat mesencephalic cell culture (Matsuura et al., 2001). FGF8 and Shh only weakly induce TH-positive cells in rat striatal cultures or human NT2 cells, whereas other factors are more efficient (Stull and Iacovitti, 2001). Our results, combined with published findings, indicate that FGF8 and Shh are not required for the development of DA neurons in the ventral diencephalon. Because Rink and Wullimann (2001) have shown that DA neurons of prosomere 3 in the posterior tuberculum are, on the basis of their ascending projections to the striatum, true functional homologues of the rostral portion of A9A10 DA neurons in mammals, it will be interesting to find out whether our results on growth factor requirements for DA specification in the ventral diencephalons-posterior tuberculum also apply to mammalian substantia nigra DA neurons.

the hindbrain are unaffected. C, By $72 \mathrm{hpf}$, oep mutants lack diencephalic catecholaminergic neurons, whereas those of the hindbrain clusters are formed. $E$, By $48 \mathrm{hpf}, \mathrm{MZsur}$ mutant embryos develop few-to-no catecholaminergic neurons in the diencephalon, whereas the LC appears normal. White arrows indicate absence of $\operatorname{PrC}$; white arrowheads indicate absence of vDD. $A D$, Amacrine dopaminergic neurons; vDD, ventral diencephalic dopaminergic neurons; $M C$, medulla oblongata catecholaminergic neurons; PrC, pretectal catecholaminergic neurons. Scale bars, $100 \mu \mathrm{m}$. 


\section{DA specification in the pretectum and ventral diencephalon requires Nodal signaling}

We observed little to no DA-NA neurons in the pretectal area and ventral diencephalon in zebrafish nodal pathway mutants lacking the Cyc/Ndr2 signal, Nodal coreceptor Oep, or downstream transcription factor Sur/FoxH1. In cyc and oep mutant embryos, the ventral diencephalon, including the hypothalamus and basal plate portion of p3, fails to form (Varga et al., 1999; Rohr et al., 2001). Thus, the lack of DA neurons in $\mathrm{p} 3$ of these mutants can be explained by the absence of the corresponding ventral diencephalic areas. Recently, Mathieu et al. (2002) showed that TH immunoreactivity can be restored in the ventral diencephalon of MZoep embryos if mesendoderm development is rescued by overexpression of an activated form of a putative Nodal receptor, Taram A. These results indicate that Nodal signaling, via interactions with the mesendoderm, could be indirectly required for ventral diencephalic DA specification. However, it is also possible that, in this experiment, the prospective $\mathrm{TH}$ immunoreactive cells in the ventral diecephalon had inherited injected RNA leading to activation of Nodal signaling within these cells themselves. In contrast, our finding that, in MZsur mutant embryos, p3 is present but DA neurons are reduced or even absent indicates that the Nodal pathway is more directly involved in DA neuron specification. Moreover, the lack of pretectal CA neurons in Nodal pathway mutants, in which the pretectum forms, supports the idea that the Nodal pathway is involved in CA fate specification.

Cell and tissue culture studies have shown that ligands of the TGF $\beta$ superfamily affect survival and differentiation of CA neurons (Poulsen et al., 1994; Jordan et al., 1997; Reiriz et al., 1999; Strelau et al., 2000; Stull and Iacovitti, 2001; Stull et al., 2001) and induce catecholaminergic differentiation in neural crest cells (Shah et al., 1996). Lints and Emmons (1999) studied the effect of Nodal/DBL-1 pathway mutants on the expression of a cat-2(TH)::gfp reporter gene in C. elegans. The formation of dopaminergic cells in ray sensory neurons was disrupted in all mutants in which DBL-1 pathway signaling was affected. However, the mechanisms by which Nodal or TGF $\beta$ ligands may affect CA differentiation are unknown. The TGF $\beta$ pathway is a complex network with intensive crosstalk between other signaling pathways (Zhang and Derynck, 1999; Massague, 2000). For example, Activin, a Nodal-related molecule, acts together with FGF2 to drive expression of $\mathrm{TH}$ in progenitors of forebrain catecholaminergic neurons in culture (Daadi et al., 1998). Rather than affecting CA differentiation directly, TGF $\beta$ signaling may indirectly affect the activity of factors required for CA differentiation, such as those that are postulated to bind to the octamer/POU, SP1, AP1, and CRE-binding sites in the promoters of several mammalian TH genes (Harrington et al., 1987; Coker et al., 1988; Kobayashi et al., 1988; Cambi et al., 1989; D’Mello et al., 1989).

Alternatively, because the nodal-related genes $c y c$ and $s q t$, as well as the receptor oep and signal transducer sur, are not expressed at late stages in the ventral diencephalon, the Nodal/ TGF $\beta$ pathway may be required for the development of DA neuron precursors. In the mouse, the homeobox-containing transcription factor pitx3 is expressed in mesencephalic DA precursors and DA neurons (Smidt et al., 1997). Zebrafish have a closely related pitx3 gene that is expressed in the ventral diencephalon in the region in which the first DA neurons develop (Z. Varga, personal communication). The expression of the zebrafish pitx gene family member pitx2, which is also expressed early in the prechordal plate and later in the hypothalamus, depends on nodal signaling (Essner et al., 2000; Faucourt et al., 2001). Thus, the dependence of ventral diencephalic CA neurons

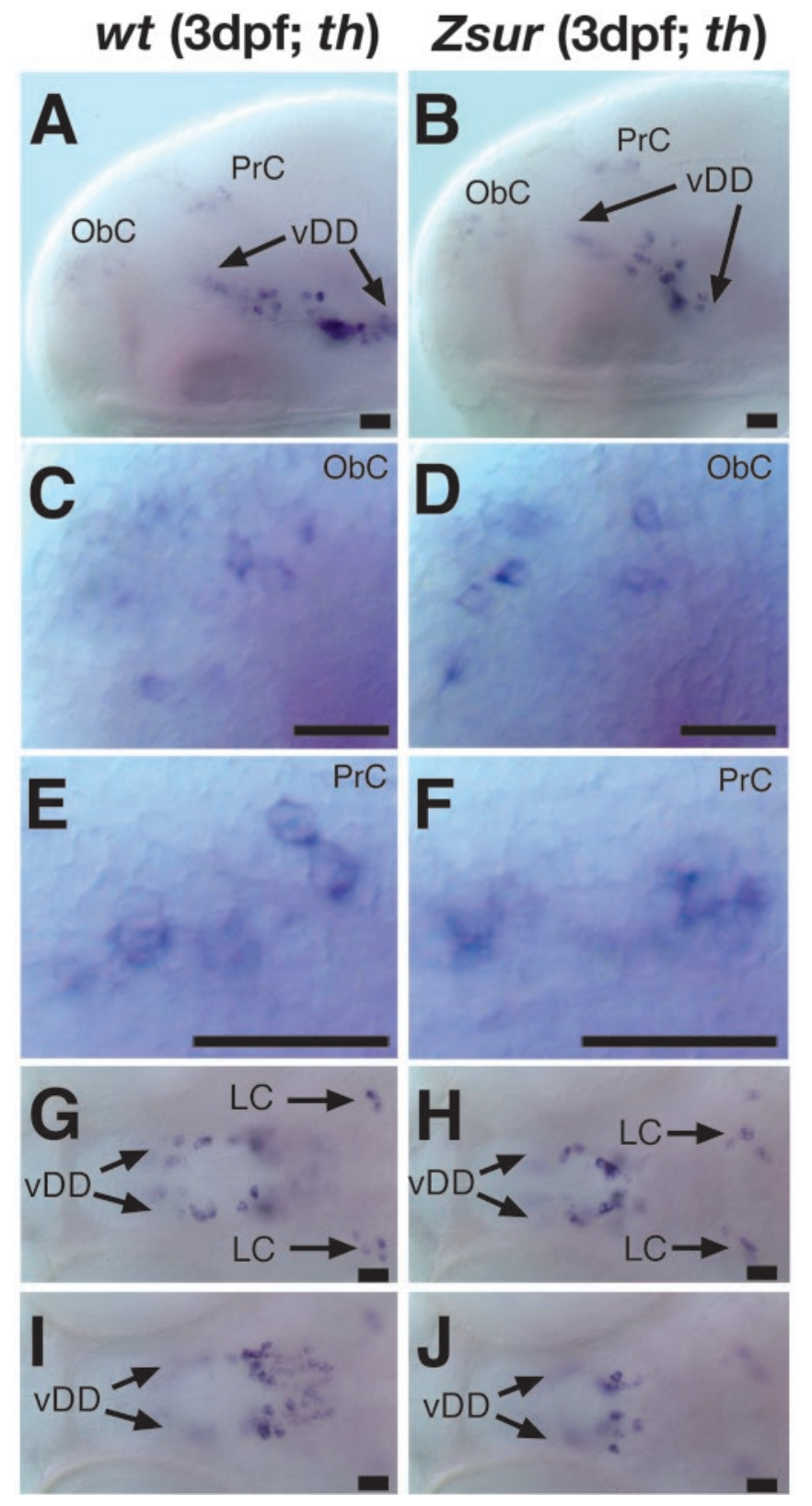

Figure 8. Formation of catecholaminergic neurons is affected in the ventral diencephalon of Zsur mutant embryos. $A-J$, Lateral views $(A-F)$ (anterior is to the left, dorsal is to the top) and dorsal views $(G-J)$ of th expression in the brain of wild-type $(A, C, E, G, I)$ and Zsur mutant $(B, D, F, H, J)$ embryos at $3 \mathrm{dpf}$. $A-F$, Overview of the catecholaminergic neurons $(A, B)$, olfactory bulbs $(C, D)$, and pretectum $(E, F)$. In the ventral diencephalon of Zsur mutant embryos, the dopaminergic neurons are reduced in the posterior tuberculum $(G, H)$ and hypothalamus $(I, J)$. The $L C(G, H)$ develops normally in Zsur mutants. vDD, Ventral diencephalic dopaminergic neurons; $\mathrm{ObC}$, olfactory bulb catecholaminergic neurons; $\mathrm{PrC}$, pretectal catecholaminergic neurons. Scale bars, $17 \mu \mathrm{m}$.

on Nodal signaling may be caused by a requirement for Nodal to induce expression of pitx genes in CA precursor cells.

\section{Formation of pretectal CA neurons depends on $\mathrm{Hh}$ and Nodal signaling}

Formation of the pretectal DA-NA neurons requires $\mathrm{Hh}$ and Nodal signaling. In mutants affecting either signaling pathway, the pretectal cluster of DA-NA neurons is reduced or deleted. Hh signaling has been shown to act downstream of Nodal signaling 


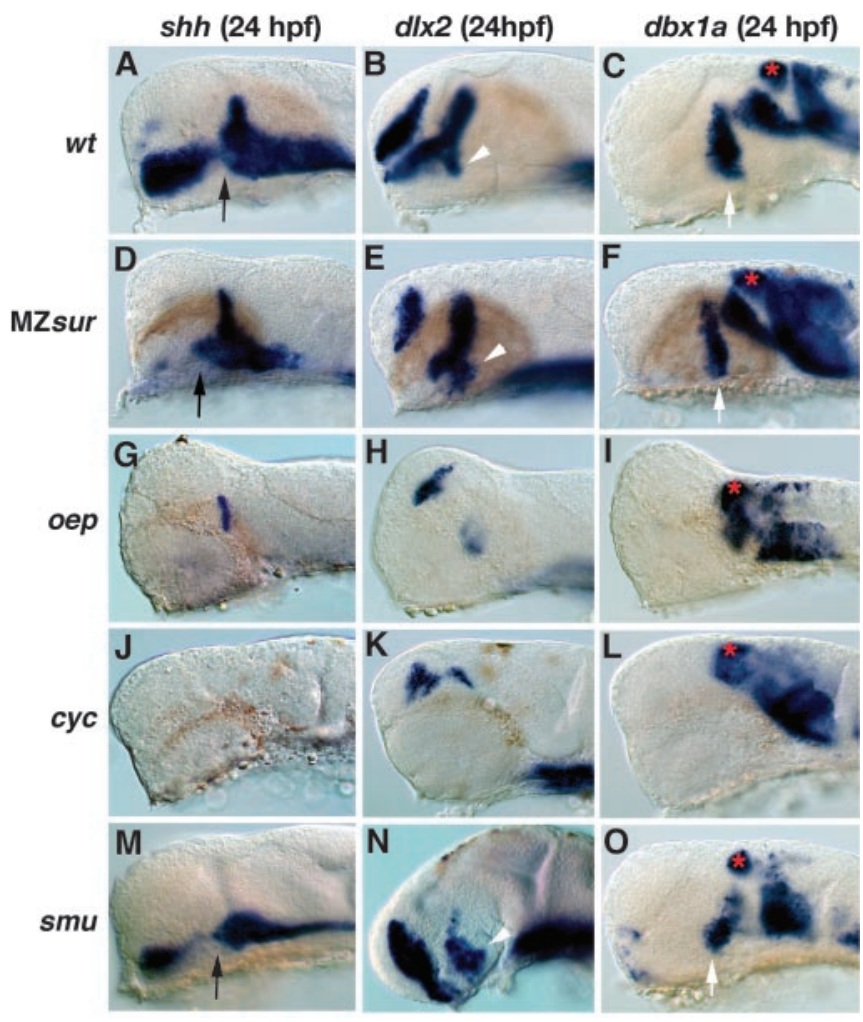

Figure 9. Embryonic patterning defects in the diencephalon of Nodal pathway and $s m u$ mutants. $A-0$, Embryos at $24 \mathrm{hpf}$ (lateral views; anterior is to the left, dorsal is to the top). $A-C$, Wild-type embryos showing the expression domains of $\operatorname{shh}(A), d 1 \times 2(B)$, and $d b \times 1 a(C) . D-F$, In MZsur embryos, shh expression is maintained in the zona limitans, part of the hypothalamus and midline $(D)$, the expression domain of $d / x 2$ in the hypothalamus is reduced in size $(E)$; and the $d b x 1 a$ expression domains in the pretectum and ventral diencephalon are present $(F) . G-I$, oep mutant embryos show no hypothalamic expression of $\operatorname{shh}(G), d \times x 2(H)$, and $d b \times 1 a(I)$, whereas the pretectal $d b \times 1 a$ domain is present. $J-L$, In cyc mutant embryos, expression of shh $(J)$, the ventral expression domains of $d \mid \times 2(K)$, and $d b \times 1 a(L)$ in the forebrain are absent, whereas $d b \times 1 a$ expression in the pretectum is present. $M-0$, In $s m u$ mutant embryos, the expression of $\operatorname{shh}(M)$ in the zona limitans is absent, but a reduced expression in the ventral brain remains. The hypothalamic expression domains of $d \mid x 2(N)$ and $d b \times 1 a(0)$, as well as the pretectal $d b \times 1 a$ domain can still be detected. The black arrows indicate the expression domain of $s h h$ in the ventral diencephalons. White arrowheads point to the $d / x 2$ domain and white arrows point to the $d b \times 1 a$ domain in the ventral diencephalons. The red stars indicate the expression domain of $d b x 1 a$ in the pretectum.

in patterning the telencephalon (Rohr et al., 2001). The expression of shh in the neuroectoderm requires Nodal signaling, because Fast 1 and Smad2 bind to the shh promoter (Muller et al., 1999). Thus, the loss of the pretectal CA-DA neurons after disruption of Nodal signaling could be caused by loss of shh expression. In sur/foxH1 mutant embryos, the loss of DA-NA neurons is less pronounced than in oep or cyc mutant embryos, which correlates with the finding that some shh expression remains in sur/foxH1 mutants. Shh acts as a morphogen, inducing various cell types from ventral neurectodermal progenitors in the neural tube in a concentration-dependent manner (Marti et al., 1995; Roelink et al., 1995; Ericson et al., 1996, 1997; Briscoe and Ericson, 1999, 2001; Briscoe et al., 2000). The Hh coreceptor Smoothened is expressed maternally and broadly expressed zygotically during early development in zebrafish, but expression later becomes progressively restricted (Chen et al., 2001; Varga et al., 2001). At 2 dpf, smoothened expression is confined to the jaw cartilage and dorsal brain including the pretectum (Varga et al., 2001; Z. Varga, personal communication). The source for Shh is
Table 2. Comparison of CA neuronal cluster development and early neural patterning defects in the diencephalon of Nodal pathway and smu mutant embryos

\begin{tabular}{lccccc}
\hline & wt & MZsur & oep & cyc & smu \\
\hline Posterior tuberculum/hypothalamus & & & & & \\
$\quad$ shh & + & + & 0 & 0 & + \\
$\quad$ Diencephalic DA cluster & + & -10 & 0 & 0 & + \\
$\quad$ Ventral thalamus alar plate & & & & & \\
$\quad d / \times 2$ & + & + & 0 & 0 & + \\
$\quad$ Diencephalic DA cluster & + & -10 & 0 & 0 & + \\
Ventral thalamus/posterior tuberculum/hypothalamus & & & & & \\
$\quad h / x 1 / d b \times 1 a$ & + & + & 0 & 0 & + \\
$\quad$ Diencephalic DA cluster & + & -10 & 0 & 0 & + \\
Pretectum & & & & & \\
$\quad h / \times 1 / d b \times 1 a$ & + & & + & + & + \\
$\quad$ Pretectal CA cluster & + & N.D. & 0 & 0 & 0 \\
\hline
\end{tabular}

$\overline{\text { Ventral diencephalic expression domains of } \operatorname{sh}, \mathrm{d} / \times 2 \text {, and } h / \times 1 / d b \times 1 a \text { mark the area in which the first dopaminergic }}$ neurons develop. The expression domain of $h / \times 1 / d b \times 1 a$ in the pretectum at $24 \mathrm{hpf}$ marks the developing pretectum, in which the pretectal CA neurons will differentiate at $72 \mathrm{hpf}$. +, Not affected or only slight changes; 0 , absent; -10 , strongly reduced or absent; N.D., not determined.

likely the zona limitans intrathalamica (ZLI). Given the distance of DA neurons from the ZLI, this implies that a low concentration of Shh may be sufficient for the induction of CA-DA neurons in the pretectum. In both Drosophila and mice, it has been shown that Hh proteins can act via long-range signaling (Huang and Kunes, 1996, 1998; Gritli-Linde et al., 2001). A possible explanation for the apparent lack of Shh involvement in the differentiation of DA neurons in the hypothalamus is that these neurons receive a much higher concentration of Shh compared with those in the pretectum. The onset of TH expression in the midbrain DA precursors in mice occurs after shh expression begins to decrease in the ventral medial midbrain (Wallen et al., 1999). Thus, in mammals too, high concentrations of Shh may repress DA differentiation. So far, it is not well understood how Hh signaling facilitates the differentiation of DA neurons, which target genes of shh signaling might mediate this effect, and how exactly Nodal signaling is involved in this process.

In summary, our comprehensive lack-of-function in vivo genetic data provide the novel opportunity to evaluate the contributions of various signaling pathways and signaling centers to the development of the CA system. Our findings indicate that the previously dominating concept in which an epigenetic grid of Shh and FGF8 specified all DA neurons is unlikely, and suggest a new signaling framework in which a prepattern evolved in the neurectoderm during gastrulation, followed by Nodal, Shh, FGF8, and other signals, specifies the earliest DA and NA neurons in the forebrain and anterior hindbrain.

\section{References}

Akimenko MA, Ekker M, Wegner J, Lin W, Westerfield M (1994) Combinatorial expression of three zebrafish genes related to distal-less: part of a homeobox gene code for the head. J Neurosci 14:3475-3486.

Belting HG, Hauptmann G, Meyer D, Abdelilah-Seyfried S, Chitnis A, Eschbach C, Soll I, Thisse C, Thisse B, Artinger KB, Lunde K, Driever W (2001) spiel ohne grenzen/pou2 is required during establishment of the zebrafish midbrain-hindbrain boundary organizer. Development 128:4165-4176.

Brand M, Heisenberg CP, Jiang YJ, Beuchle D, Lun K, Furutani-Seiki M, Granato M, Haffter P, Hammerschmidt M, Kane DA, Kelsh RN, Mullins MC, Odenthal J, van Eeden FJ, Nusslein-Volhard C (1996) Mutations in zebrafish genes affecting the formation of the boundary between midbrain and hindbrain. Development 123:179-190.

Briscoe J, Ericson J (1999) The specification of neuronal identity by graded Sonic Hedgehog signaling. Semin Cell Dev Biol 10:353-362. 
Briscoe J, Ericson J (2001) Specification of neuronal fates in the ventral neural tube. Curr Opin Neurobiol 11:43-49.

Briscoe J, Pierani A, Jessell TM, Ericson J (2000) A homeodomain protein code specifies progenitor cell identity and neuronal fate in the ventral neural tube. Cell 101:435-445.

Burgess S, Reim G, Chen W, Hopkins N, Brand M (2002) The zebrafish spiel-ohne-grenzen (spg) gene encodes the POU domain protein Pou2 related to mammalian Oct4 and is essential for formation of the midbrain and hindbrain, and for pre-gastrula morphogenesis. Development 129:905-916.

Cambi F, Fung B, Chikaraishi D (1989) 5' flanking DNA sequences direct cell-specific expression of rat tyrosine hydroxylase. J Neurochem 53:1656-1659.

Chen W, Burgess S, Hopkins N (2001) Analysis of the zebrafish smoothened mutant reveals conserved and divergent functions of hedgehog activity. Development 128:2385-2396.

Coker III GT, Vinnedge L, O'Malley KL (1988) Characterization of rat and human tyrosine hydroxylase genes: functional expression of both promoters in neuronal and non-neuronal cell types. Biochem Biophys Res Commun 157:1341-1347.

Concha ML, Burdine RD, Russell C, Schier AF, Wilson SW (2000) A nodal signaling pathway regulates the laterality of neuroanatomical asymmetries in the zebrafish forebrain. Neuron 28:399-409.

Currie PD, Ingham PW (1996) Induction of a specific muscle cell type by a hedgehog-like protein in zebrafish. Nature 382:452-455.

Daadi M, Arcellana-Panlilio MY, Weiss S (1998) Activin co-operates with fibroblast growth factor 2 to regulate tyrosine hydroxylase expression in the basal forebrain ventricular zone progenitors. Neuroscience 86:867-880.

Dahlström A, Fuxe K (1964) Evidence for the existence of monoamine containing neurons in the central nervous system. I. Demonstration of monoamines in the cell bodies of the brain stem neurons. Acta Neuropathol [Suppl] 232:1-55.

Dick A, Mayr T, Bauer H, Meier A, Hammerschmidt M (2000) Cloning and characterization of zebrafish $\operatorname{smad} 2, \operatorname{smad} 3$ and $\operatorname{smad} 4$. Gene 246:69-80.

D’Mello SR, Turzai LM, Gioio AE, Kaplan BB (1989) Isolation and structural characterization of the bovine tyrosine hydroxylase gene. J Neurosci Res 23:31-40.

Ekker SC, Ungar AR, Greenstein P, von Kessler DP, Porter JA, Moon RT, Beachy PA (1995) Patterning activities of vertebrate hedgehog proteins in the developing eye and brain. Curr Biol 5:944-955.

Ericson J, Morton S, Kawakami A, Roelink H, Jessell TM (1996) Two critical periods of Sonic Hedgehog signaling required for the specification of motor neuron identity. Cell 87:661-673.

Ericson J, Rashbass P, Schedl A, Brenner-Morton S, Kawakami A, van Heyningen V, Jessell TM, Briscoe J (1997) Pax6 controls progenitor cell identity and neuronal fate in response to graded Shh signaling. Cell 90:169-180.

Essner JJ, Branford WW, Zhang J, Yost HJ (2000) Mesendoderm and leftright brain, heart and gut development are differentially regulated by pitx2 isoforms. Development 127:1081-1093.

Faucourt M, Houliston E, Besnardeau L, Kimelman D, Lepage T (2001) The pitx2 homeobox protein is required early for endoderm formation and nodal signaling. Dev Biol 229:287-306.

Fjose A, Izpisua-Belmonte JC, Fromental-Ramain C, Duboule D (1994) Expression of the zebrafish gene hlx-1 in the prechordal plate and during CNS development. Development 120:71-81.

Furthauer M, Thisse C, Thisse B (1997) A role for FGF-8 in the dorsoventral patterning of the zebrafish gastrula. Development 124:4253-4264.

Gritli-Linde A, Lewis P, McMahon AP, Linde A (2001) The whereabouts of a morphogen: direct evidence for short- and graded long-range activity of hedgehog signaling peptides. Dev Biol 236:364-386.

Gritsman K, Zhang J, Cheng S, Heckscher E, Talbot WS, Schier AF (1999) The EGF-CFC protein one-eyed pinhead is essential for nodal signaling. Cell 97:121-132.

Guo S, Wilson SW, Cooke S, Chitnis AB, Driever W, Rosenthal A (1999a) Mutations in the zebrafish unmask shared regulatory pathways controlling the development of catecholaminergic neurons. Dev Biol 208:473-487.

Guo S, Brush J, Teraoka H, Goddard A, Wilson SW, Mullins MC, Rosenthal A (1999b) Development of noradrenergic neurons in the zebrafish hind- brain requires BMP, FGF8, and the homeodomain protein soulless/ Phox2a. Neuron 24:555-566.

Guo S, Yamaguchi Y, Schilbach S, Wada T, Lee J, Goddard A, French D, Handa H, Rosenthal A (2000) A regulator of transcriptional elongation controls vertebrate neuronal development. Nature 408:366-369.

Harrington CA, Lewis EJ, Krzemien D, Chikaraishi DM (1987) Identification and cell type specificity of the tyrosine hydroxylase gene promoter. Nucleic Acids Res 15:2363-2384.

Hatta K, Kimmel CB, Ho RK, Walker C (1991) The cyclops mutation blocks specification of the floor plate of the zebrafish central nervous system. Nature 350:339-341.

Hauptmann G, Gerster T (1994) Two-color whole-mount in situ hybridization to vertebrate and Drosophila embryos. Trends Genet 10:266.

Hauptmann G, Gerster T (1995) Pou-2-a zebrafish gene active during cleavage stages and in the early hindbrain. Mech Dev 51:127-138.

Hauptmann G, Gerster T (2000) Regulatory gene expression patterns reveal transverse and longitudinal subdivisions of the embryonic zebrafish forebrain. Mech Dev 91:105-118.

Holzschuh J, Ryu S, Aberger F, Driever W (2001) Dopamine transporter expression distinguishes dopaminergic neurons from other catecholaminergic neurons in the developing zebrafish embryo. Mech Dev 101:237-243.

Huang Z, Kunes S (1996) Hedgehog, transmitted along retinal axons, triggers neurogenesis in the developing visual centers of the Drosophila brain. Cell 86:411-422.

Huang Z, Kunes S (1998) Signals transmitted along retinal axons in Drosophila: hedgehog signal reception and the cell circuitry of lamina cartridge assembly. Development 125:3753-3764.

Hynes M, Rosenthal A (1999) Specification of dopaminergic and serotonergic neurons in the vertebrate CNS. Curr Opin Neurobiol 9:26-36.

Hynes M, Rosenthal A (2000) Embryonic stem cells go dopaminergic. Neuron 28:11-14.

Hynes M, Poulsen K, Tessier-Lavigne M, Rosenthal A (1995a) Control of neuronal diversity by the floor plate: contact-mediated induction of midbrain dopaminergic neurons. Cell 80:95-101.

Hynes M, Porter JA, Chiang C, Chang D, Tessier-Lavigne M, Beachy PA, Rosenthal A (1995b) Induction of midbrain dopaminergic neurons by Sonic hedgehog. Neuron 15:35-44.

Johnson WA, Hirsh J (1990) Binding of a Drosophila POU-domain protein to a sequence element regulating gene expression in specific dopaminergic neurons. Nature 343:467-470.

Jordan J, Bottner M, Schluesener HJ, Unsicker K, Krieglstein K (1997) Bone morphogenetic proteins: neurotrophic roles for midbrain dopaminergic neurons and implications of astroglial cells. Eur J Neurosci 9:1699-1709.

Kaslin J, Panula P (2001) Comparative anatomy of the histaminergic and other aminergic systems in zebrafish (Danio rerio). J Comp Neurol 440:342-377.

Kimmel CB, Ballard WW, Kimmel SR, Ullmann B, Schilling TF (1995) Stages of embryonic development of the zebrafish. Dev Dyn 203:253-310.

Kobayashi K, Kaneda N, Ichinose H, Kishi F, Nakazawa A, Kurosawa Y, Fujita K, Nagatsu T (1988) Structure of the human tyrosine hydroxylase gene: alternative splicing from a single gene accounts for generation of four mRNA types. J Biochem (Tokyo) 103:907-912.

Krauss S, Johansen T, Korzh V, Moens U, Ericson JU, Fjose A (1991) Zebrafish pax[zf-a]: a paired box-containing gene expressed in the neural tube. EMBO J 10:3609-3619.

Krauss S, Concordet JP, Ingham PW (1993) A functionally conserved homolog of the Drosophila segment polarity gene hh is expressed in tissues with polarizing activity in zebrafish embryos. Cell 75:1431-1444.

Lee SH, Lumelsky N, Studer L, Auerbach JM, McKay RD (2000) Efficient generation of midbrain and hindbrain neurons from mouse embryonic stem cells. Nat Biotechnol 18:675-679.

Lints R, Emmons SW (1999) Patterning of dopaminergic neurotransmitter identity among Caenorhabditis elegans ray sensory neurons by a TGFbeta family signaling pathway and a Hox gene. Development 126:5819-5831.

Liu A, Losos K, Joyner A (1999) FGF8 can activate Gbx2 and transform regions of the rostral mouse brain into a hindbrain fate. Development 126:4827-4838.

Lun K, Brand M (1998) A series of no isthmus (noi) alleles of the zebrafish pax2.1 gene reveals multiple signaling events in development of the midbrain-hindbrain boundary. Development 125:3049-3062. 
Ma PM (1994a) Catecholaminergic systems in the zebrafish. I. Number, morphology, and histochemical characteristics of neurons in the locus coeruleus. J Comp Neurol 344:242-255.

Ma PM (1994b) Catecholaminergic systems in the zebrafish. II. Projection pathways and pattern of termination of the locus coeruleus. J Comp Neurol 344:256-269.

Ma PM (1997) Catecholaminergic systems in the zebrafish. III. Organization and projection pattern of medullary dopaminergic and noradrenergic neurons. J Comp Neurol 381:411-427.

Macdonald R, Xu Q, Barth KA, Mikkola I, Holder N, Fjose A, Krauss S, Wilson SW (1994) Regulatory gene expression boundaries demarcate sites of neuronal differentiation in the embryonic zebrafish forebrain. Neuron 13:1039-1053.

Macdonald R, Scholes J, Strahle U, Brennan C, Holder N, Brand M, Wilson SW (1997) The Pax protein Noi is required for commissural axon pathway formation in the rostral forebrain. Development 124:2397-2408.

Marti E, Bumcrot DA, Takada R, McMahon AP (1995) Requirement of 19K form of Sonic hedgehog for induction of distinct ventral cell types in CNS explants. Nature 375:322-325.

Massague J (2000) How cells read TGF-beta signals. Nat Rev Mol Cell Biol $1: 169-178$.

Mathieu J, Barth A, Rosa FM, Wilson SW, Peyrieras N (2002) Distinct and cooperative roles for Nodal and Hedgehog signals during hypothalamic development. Development 129:3055-3065.

Matsuura N, Lie DC, Hoshimaru M, Asahi M, Hojo M, Ishizaki R, Hashimoto N, Noji S, Ohuchi H, Yoshioka H, Gage FH (2001) Sonic hedgehog facilitates dopamine differentiation in the presence of a mesencephalic glial cell line. J Neurosci 21:4326-4335.

Meek J (1994) Catecholamines in the brain of Osteichtyes (bony fishes). In: Phylogeny and development of catecholamine systems in the CNS of vertebrates (Smeets WJAJ, Reiner A, eds), pp 49-74. Cambridge, UK: Cambridge UP.

Morita K, Chow KL, Ueno N (1999) Regulation of body length and male tail ray pattern formation of Caenorhabditis elegans by a member of TGF-beta family. Development 126:1337-1347.

Muller F, Chang B, Albert S, Fischer N, Tora L, Strahle U (1999) Intronic enhancers control expression of zebrafish sonic hedgehog in floor plate and notochord. Development 126:2103-2116.

Newfeld SJ, Wisotzkey RG, Kumar S (1999) Molecular evolution of a developmental pathway: phylogenetic analyses of transforming growth factorbeta family ligands, receptors and Smad signal transducers. Genetics 152:783-795.

Odenthal J, van Eeden FJ, Haffter P, Ingham PW, Nusslein-Volhard C (2000) Two distinct cell populations in the floor plate of the zebrafish are induced by different pathways. Dev Biol 219:350-363.

Pattyn A, Goridis C, Brunet JF (2000) Specification of the central noradrenergic phenotype by the homeobox gene Phox2b. Mol Cell Neurosci 15:235-243.

Pogoda HM, Meyer D (2002) Zebrafish smad7 is regulated by Smad3 and BMP signals. Dev Dyn 224:334-349.

Pogoda HM, Solnica-Krezel L, Driever W, Meyer D (2000) The zebrafish forkhead transcription factor FoxH1/Fast1 is a modulator of nodal signaling required for organizer formation. Curr Biol 10:1041-1049.

Poulsen KT, Armanini MP, Klein RD, Hynes MA, Phillips HS, Rosenthal A (1994) TGF beta 2 and TGF beta 3 are potent survival factors for midbrain dopaminergic neurons. Neuron 13:1245-1252.

Rebagliati MR, Toyama R, Haffter P, Dawid IB (1998) cyclops encodes a nodal-related factor involved in midline signaling. Proc Natl Acad Sci USA 95:9932-9937.

Reifers F, Bohli H, Walsh EC, Crossley PH, Stainier DY, Brand M (1998) Fgf8 is mutated in zebrafish acerebellar (ace) mutants and is required for maintenance of midbrain-hindbrain boundary development and somitogenesis. Development 125:2381-2395.

Reifers F, Adams J, Mason IJ, Schulte-Merker S, Brand M (2000) Overlapping and distinct functions provided by fgf17, a new zebrafish member of the Fgf8/17/18 subgroup of Fgfs. Mech Dev 99:39-49.

Reiriz J, Espejo M, Ventura F, Ambrosio S, Alberch J (1999) Bone morphogenetic protein-2 promotes dissociated effects on the number and differentiation of cultured ventral mesencephalic dopaminergic neurons. J Neurobiol 38:161-170.

Rink E, Wullimann MF (2001) The teleostean (zebrafish) dopaminergic system ascending to the subpallium (striatum) is located in the basal diencephalon (posterior tuberculum). Brain Res 889:316-330.

Rink E, Wullimann MF (2002) Development of the catecholaminergic system in the early zebrafish brain: an immunohistochemical study. Brain Res Dev Brain Res 137:89-100.

Roelink H, Porter JA, Chiang C, Tanabe Y, Chang DT, Beachy PA, Jessell TM (1995) Floor plate and motor neuron induction by different concentrations of the amino-terminal cleavage product of sonic hedgehog autoproteolysis. Cell 81:445-455.

Rohr KB, Barth KA, Varga ZM, Wilson SW (2001) The nodal pathway acts upstream of hedgehog signaling to specify ventral telencephalic identity. Neuron 29:341-351.

Rubenstein JL, Beachy PA (1998) Patterning of the embryonic forebrain. Curr Opin Neurobiol 8:18-26.

Sampath K, Rubinstein AL, Cheng AM, Liang JO, Fekany K, Solnica-Krezel L, Korzh V, Halpern ME, Wright CV (1998) Induction of the zebrafish ventral brain and floorplate requires cyclops/nodal signalling. Nature 395:185-189.

Schauerte HE, van Eeden FJ, Fricke C, Odenthal J, Strahle U, Haffter P (1998) Sonic hedgehog is not required for the induction of medial floor plate cells in the zebrafish. Development 125:2983-2993.

Shah NM, Groves AK, Anderson DJ (1996) Alternative neural crest cell fates are instructively promoted by TGFbeta superfamily members. Cell 85:331-343.

Simon HH, Saueressig H, Wurst W, Goulding MD, O’Leary DD (2001) Fate of midbrain dopaminergic neurons controlled by the engrailed genes. J Neurosci 21:3126-3134.

Sirotkin HI, Gates MA, Kelly PD, Schier AF, Talbot WS (2000) Fast1 is required for the development of dorsal axial structures in zebrafish. Curr Biol 10:1051-1054

Smeets WJ, Gonzalez A (2000) Catecholamine systems in the brain of vertebrates: new perspectives through a comparative approach. Brain Res Brain Res Rev 33:308-379.

Smeets WJAJ, Reiner A (1994) Phylogeny and development of catecholamine systems in the CNS of vertebrates. Cambridge, UK: Cambridge UP.

Smidt MP, van Schaick HS, Lanctot C, Tremblay JJ, Cox JJ, van der Kleij AA, Wolterink G, Drouin J, Burbach JP (1997) A homeodomain gene Ptx3 has highly restricted brain expression in mesencephalic dopaminergic neurons. Proc Natl Acad Sci USA 94:13305-13310.

Smidt MP, Asbreuk CH, Cox JJ, Chen H, Johnson RL, Burbach JP (2000) A second independent pathway for development of mesencephalic dopaminergic neurons requires Lmxlb. Nat Neurosci 3:337-341.

Strähle U, Blader P, Ingham PW (1996) Expression of axial and sonic hedgehog in wildtype and midline defective zebrafish embryos. Int J Dev Biol 40:929-940.

Strelau J, Sullivan A, Bottner M, Lingor P, Falkenstein E, Suter-Crazzolara C, Galter D, Jaszai J, Krieglstein K, Unsicker K (2000) Growth/differentiation factor-15/macrophage inhibitory cytokine-1 is a novel trophic factor for midbrain dopaminergic neurons in vivo. J Neurosci 20:8597-8603.

Stull ND, Iacovitti L (2001) Sonic hedgehog and FGF8: inadequate signals for the differentiation of a dopamine phenotype in mouse and human neurons in culture. Exp Neurol 169:36-43.

Stull ND, Jung JW, Iacovitti L (2001) Induction of a dopaminergic phenotype in cultured striatal neurons by bone morphogenetic proteins. Brain Res Dev Brain Res 130:91-98.

Suzuki Y, Yandell MD, Roy PJ, Krishna S, Savage-Dunn C, Ross RM, Padgett RW, Wood WB (1999) A BMP homolog acts as a dose-dependent regulator of body size and male tail patterning in Caenorhabditis elegans. Development 126:241-250.

Twyman RM, Jones EA (1995) The regulation of neuron-specific gene expression in the mammalian nervous system. J Neurogenet 10:67-101.

Varga ZM, Wegner J, Westerfield M (1999) Anterior movement of ventral diencephalic precursors separates the primordial eye field in the neural plate and requires cyclops. Development 126:5533-5546.

Varga ZM, Amores A, Lewis KE, Yan YL, Postlethwait JH, Eisen JS, Westerfield M (2001) Zebrafish smoothened functions in ventral neural tube specification and axon tract formation. Development 128:3497-3509.

Wallen A, Zetterstrom RH, Solomin L, Arvidsson M, Olson L, Perlmann T (1999) Fate of mesencephalic AHD2-expressing dopamine progenitor cells in NURR1 mutant mice. Exp Cell Res 253:737-746.

Wang MZ, Jin P, Bumcrot DA, Marigo V, McMahon AP, Wang EA, Woolf T, 
Pang K (1995) Induction of dopaminergic neuron phenotype in the midbrain by Sonic hedgehog protein. Nat Med 1:1184-1188.

Westerfield M (1995) The zebrafish book. A guide for the laboratory use of zebrafish (Danio rerio), Ed 3. Eugene, OR: University of Oregon.

Wullimann MF, Puelles L (1999) Postembryonic neural proliferation in the zebrafish forebrain and its relationship to prosomeric domains. Anat Embryol (Berl) 199:329-348.

Wullimann MF, Rink E (2001) Detailed immunohistology of Pax6 protein and tyrosine hydroxylase in the early zebrafish brain suggests role of Pax6 gene in development of dopaminergic diencephalic neurons. Brain Res Dev Brain Res 131:173-191.

Wurst W, Auerbach AB, Joyner AL (1994) Multiple developmental defects in Engrailed-1 mutant mice: an early mid-hindbrain deletion and patterning defects in forelimbs and sternum. Development 120: 2065-2075.

Ye W, Shimamura K, Rubenstein JL, Hynes MA, Rosenthal A (1998) FGF and Shh signals control dopaminergic and serotonergic cell fate in the anterior neural plate. Cell 93:755-766.

Zetterstrom RH, Solomin L, Jansson L, Hoffer BJ, Olson L, Perlmann T (1997) Dopamine neuron agenesis in Nurrl-deficient mice. Science 276:248-250

Zhang J, Talbot WS, Schier AF (1998) Positional cloning identifies zebrafish one-eyed pinhead as a permissive EGF-related ligand required during gastrulation. Cell 92:241-251.

Zhang Y, Derynck R (1999) Regulation of Smad signalling by protein associations and signalling crosstalk. Trends Cell Biol 9:274-279. 